\title{
Pilot Study for Validity and Reliability of an Aptitude Test
}

\author{
Mehwish Noor \\ Department of English, University of Gujrat, Punjab, Pakistan; Email: noorlinguist@gmail.com \\ Bahram Kazemian (Corresponding Author) \\ Department of English, Tabriz Branch, Islamic Azad University, Tabriz, Iran; Email: bahram_kazemian@yahoo.com \\ Raza-e-Mustafa \\ Department of English, University of Gujrat, Punjab, Pakistan; razaemustafa@uog.edu.pk \\ Fakharh Muhabat \\ Department of English, University of Gujrat, Punjab, Pakistan; Email: biyakhan38@yahoo.com

\begin{abstract}
The study was conducted in the department of the English University of Gujrat during Spring- 2012 semester. A question paper was designed to check the aptitude of the intermediate students of population 25. There were three sections; Grammar, vocabulary and reading comprehension, in the question paper. Section: A (Grammar) was proved valid with $84.33 \%$ of validity. The validity of Section: B (vocabulary) and Section C (reading comprehension) were $91.64 \%$ and 52.00 respectively. As a whole, the validity of all the questions was $75.99 \%$. Thus, the designed aptitude test may be considered reliable.
\end{abstract}

Doi:10.5901/jesr.2015.v5n3p285

Keywords: Validity, Reliability, Aptitude Test, Reading Comprehension, Grammar and Vocabulary.

\section{Introduction}

Evaluation and assessment are very important elements of the process of learning and teaching. They provide significance and weight to the mentioned process. A number of issues are involved to set a good test. It is almost ideal to set a valid and reliable test in order to intervene it with the pre-set objectives of teaching. The objectives of teaching a specific course or module must be relevant to the need analysis of the learners, time, place, resources and the institution. Assessment is very expedient for students who need feedback, for teachers who need information about their students' understanding, for academic institutions that need information about the process of teaching and learning and for parents who need information about their children's progress. Assessment is a good source of wash back, negative and positive. Experienced teachers use assessment as an evidence of learning to inform what and how they have taught. On the other hand, tests may encourage students to study more or may promote their standards of learning. Tests actually appraise the students' cognitive abilities, performance, and potential of learning. They also gauge the validity and reliability of the test in order to fulfill the pre-planned objectives. Cameron (1963) contended that "Not everything that counts can be counted, and not everything that can be counted counts". In fact, there is no universal agreement as to which human processes are responsible for the improvement in intelligent behavior and no clear consensus to measure human mental capabilities. It includes the capacity to learn from experience, process information and adapt to the environment. However, tests are designed to quantify a variety of cognitive processes that underlie one's capability. Bower (2009) is of the opinion that assessment is not a spreadsheet rather it is a conversation. It is not a perplexing activity rather it is an exchange of the information that teachers and the learners require in order to improve their performances.

Aptitude tests are primarily designed to predict future outcomes of success. They mainly aim at the potential capabilities of the learners in a particular domain. They are used in a recruitment process. Predominantly, an aptitude test does not examine knowledge; it is not a test that one can study for. There is no syllabus fixed for this kind of tests because they are used to determine an individual's tendency to succeed in a given field. Individuals might take an 
aptitude test to determine what kinds of careers they are well suited for. Similarly, college students might take an aptitude test when thinking about what would be an appropriate field of study and which university is the best choice for them. Such kind of predictive (aptitude) tests are the dire need of the age for a healthy competitive environment.

\section{Literature Review}

The practice of reliability and validity are common in quantitative research and now it is reevaluated in the qualitative research model (Golafshani, 2003). Both reliability and validity are essential in the process of designing a good test. Winter (2000) stated, "Reliability and validity are tools of an essentially positivist epistemology" (p. 7). Joppe (2000) clearly defines reliability as:

The extent to which results are consistent over time and an accurate representation of the total population under study is referred to as reliability and if the results of a study can be reproduced under a similar methodology, then the research instrument is considered to be reliable (p. 1).

She further explained validity in quantitative research as: It determines whether the research truly measures that which it was intended to measure or how truthful the research results are. In other words, does the research instrument allow you to hit "the bull's eye" of your research object? (p. 1). This study aimed at designing a valid as well as reliable test up to human level in order to achieve the desired results. Henceforth, SPSS statistical programme is applied for the analysis of a pilot study.

McClelland (1973) differentiates the intelligence test with performance test. He affirms the necessity of performance based tests in order to bring about a match between test scores and professional and academic research.

The current study is valuable by keeping in view the transparency of the process of assessment. So to say, pilot studies have been conducted to ensure the validity and reliability of the tests set not only for assessing the abilities of the students but also to predict their future performance (Hambleton, \& Patsula, 1999).

Chalmers (2007) reports about the practice of Australian government of evaluation of pilot studies since 2007 and asserts the necessity of conducting such kind of studies for the sake of prerequisite of the fair judgment. In the same line, Sabrina et al, (2007) opine the effectiveness of the meta-analysis of higher education students and for the purpose, suggest prior conformity of the actual evaluation in order to assess the skills of German speaking students. Choi (2008) reports with reference to Korea, those aptitude tests have a considerable impact on EFL learning.

Similarly, Gardner (1983) presents the social and psychological perspectives of the aptitudes test of second language proficiency and reports that it is a common practice in India, Nigeria and Maldives. He emphasizes that attention and motivation of the students of second language are of paramount importance. So that, to keep them intact, the validity and reliability of the aptitude test are very much important.

It is evident that the proficiency of English language matters for the professional and scientific studies at higher levels. So that, universities round the world offer aptitude tests in order to predict future success of the students. That is why, such kind of studies enhance the efficiency of these tests and provide a chance to improve the quality of the test prior to the actual evaluation.

\subsection{Research Objectives}

This study was carried out by keeping in mind the following objectives:

- To prepare a question paper by covering the three main areas: Grammar, vocabulary and reading comprehension of language.

- To gauge the intermediate students' language proficiency for future success through the designed question paper.

- To analyze the reliability and validity of the questions.

\subsection{Research Question}

Does the designed question paper address the objectives?

\section{Materials and Methods}

The study was conducted in the department of the English University of Gujrat during spring- 2012 semester, as a 
fulfillment of TESOL-III assignment.

For the purpose, a question paper was designed to check the aptitude of the intermediate students for their language proficiency. The question paper had three sections. The section A: had nine questions related to English Grammar. The section B: had eleven questions that covered various areas of vocabulary like analogy, synonym, antonym and general knowledge. The last section C: comprised of five questions which were asked from the given passage. For addressing proper answers, students had to go through the careful reading of the passage.

Twenty-five $(n=25)$ Second Semester BS Environmental Sciences Students (respondents) were randomly selected from the University of Gujrat. Second Semester students are fresh Intermediate students thus were preferred as per design and level of the aptitude test. The data obtained was analyzed by Statistical Software SPSS (Statistical Package for the Social Sciences).

\section{Results and Discussion}

\subsection{Section A (Grammar):}

It was observed that respondents had attempted questions in given time frame. Table \# 01, reveals the detailed analysis of the Section A (Grammar). All the nine questions were attempted by the respondents. All the asked questions proved valid except Question \# 04 and 05 . The questions were not very hard. However, the questions were proved unreliable. The reason might be the Grammar translation Method of learning, because the native language of the respondents is Urdu and they conceived the meaning accordingly that led them to attempt incorrectly. As a whole, the Section had 84.33 of validity.

Table \# 01: Detail Analysis of Section A (Grammar)

\begin{tabular}{|c|c|c|c|c|}
\hline Question \# & Correct Answer (\%) & Wrong Answer (\%) & Un-attempted (\%) & Validity of Question (\%) \\
\hline 01 & 96.00 & 04.00 & 00.00 & 96.00 \\
\hline 02 & 96.00 & 04.00 & 00.00 & 96.00 \\
\hline 03 & 88.00 & 12.00 & 00.00 & 88.00 \\
\hline 04 & 04.00 & 96.00 & 00.00 & 04.00 \\
\hline 05 & 00.00 & 100.0 & 00.00 & 00.00 \\
\hline 06 & 100.0 & 00.00 & 00.00 & 100.0 \\
\hline 07 & 100.0 & 00.00 & 00.00 & 100.0 \\
\hline 08 & 92.00 & 08.00 & 00.00 & 92.00 \\
\hline 09 & 96.00 & 04.00 & 00.00 & 96.00 \\
\hline Validity as a Whole for Section "A" & & 84.33 \\
\hline
\end{tabular}

\subsubsection{Item Analysis of Section A (Grammar)}

Q\#01: Did you -------- anywhere last weekend?

This question was attempted by $96 \%$ respondents as the correct choice, whereas only $4 \%$ of the respondents chose the wrong option. There is no evidence of the selection of any particular distracter. The question may be considered valid and reliable.

The item was selected on the assumption that the use of a first form of the verb is often problematic for second language learners. English was the second language of all the respondents thus the assumption may be considered wrong.

Q\#02: I work as a teacher and so my wife.

The majority (96\%) of the respondents selected the correct option, whereas only $4 \%$ of the respondents chose the incorrect option. There is no evidence of the selection of any particular distracter. The question may be considered valid and reliable.

The item was selected on the assumption that the proper use of the present indefinite form of the verb for the third person singular is often problematic for second language learners. The obtained data is negating the assumption.

Q\#03: How long --------- married?

Comprehensively, $88 \%$ of the respondents selected the correct option, whereas only $12 \%$ of the respondents went for the incorrect option. No evidence of the selection of any particular distracter can be seen. The question may be 
considered valid and reliable.

The item was selected on the assumption that the proper use of the Present Perfect Continuous Tense is often problematic for second language learners. Only $12 \%$ respondents proved the assumption.

Q\#04: He has not played since he -----------an accident.

Only $4 \%$ of the respondents selected the correct option, whereas only $96 \%$ of the respondents went for the incorrect option. There is no evidence of the selection of any particular distracter.

The item was selected on the assumption that the proper use of "since s/he has had" case in the present perfect form of the verb is often problematic for second language learners. Even though the item was selected according to the difficulty level of the respondents, yet it was attempted incorrectly by the majority of the students so the item was proved invalid through the SPSS data analysis. It was considered as a bad item and the reliability of the test might be increased if the item is deleted.

Q\#05: He is good----- Mathematics.

All the respondents selected the wrong option. All the respondents opted same distracter "(a) in". Although the item was selected according to the difficulty level of the respondents, yet it was attempted incorrectly by the students so the item was proved invalid. It was considered as a bad item and the reliability of the test might be increased if the item is deleted.

The selection of the specific item refers to the error analysis leads us to the fact that it occurred due to the difference between the source language and target language structures.

Q\#06: I --------a book now-a-days.

All $(100 \%)$ respondents attempted the question correctly. Thus, no evidence of the selection of the specific distracter can be seen.

The item was selected on the assumption that the use of the verb "be" is sometimes problematic for second language learners. The question is proved valid and reliable.

Q\#07: I have not seen him-------a long time.

All (100\%) of the respondents attempted the question correctly. Thus, the question is proved valid and reliable.

The item was selected on the assumption that the appropriate use of the preposition is sometimes problematic for second language learners.

Q\#08: If she works hard, she-------the test.

Most of the respondents (92\%) attempted the question correctly, whereas only $08 \%$ of the respondents chose the wrong option. There is no evidence of the selection of the specific distracter. Thus, the question is proved valid and reliable.

The item was selected on the assumption that the conditional sentences are often problematic for second language learners.

Q\#09: Zafer --------in the factory for ten years.

The majority of the respondents (96\%) selected the correct option whereas only $04 \%$ of the respondents went for the incorrect option. There is no evidence of the selection of any particular distracter. The question is proved valid and reliable.

The item was selected on the assumption that the proper use of the Present Perfect Continuous Tense in such a case is often problematic for second language learners.

\subsection{Section $B$ (vocabulary)}

Table \# 02: Detail Analysis of Section B (Vocabulary)

\begin{tabular}{|c|c|c|c|c|}
\hline Question \# & Correct Answer (\%) & Wrong Answer (\%) & Un-attempted (\%) & Validity of Question (\%) \\
\hline 10 & 88.00 & 08.00 & 04.00 & 92.00 \\
\hline 11 & 100.0 & 00.0 & 00.00 & 100.0 \\
\hline 12 & 100.0 & 00.0 & 00.00 & 100.0 \\
\hline 13 & 100.0 & 00.00 & 00.00 & 100.0 \\
\hline 14 & 68.00 & 32.00 & 00.00 & 68.00 \\
\hline 15 & 60.00 & 40.00 & 00.00 & 60.00 \\
\hline 16 & 96.00 & 04.00 & 00.00 & 96.00 \\
\hline 17 & 92.00 & 08.00 & 00.00 & 92.00 \\
\hline 18 & 100.0 & 00.00 & 00.00 & 100.0 \\
\hline
\end{tabular}




\begin{tabular}{|c|c|c|c|c|}
\hline 19 & 100.0 & 00.00 & 00.00 & 100.0 \\
\hline 20 & 100.0 & 00.00 & 00.00 & 100.0 \\
\hline \multicolumn{4}{|l|}{ Validity as a Whole for Section "B" } & 91.63 \\
\hline
\end{tabular}

It was observed that respondents had attempted questions in given time frame. Table \# 02 reveals the detailed analysis of the section: B (Vocabulary). Except the item \#10, all the eleven questions were attempted by the respondents. 04.00\% of the respondents did not attempt it. All the asked questions proved valid through the SPSS data analysis.

\subsubsection{Item Analysis of Section B (Vocabulary)}

Q\#10: Cow: Calf:

$88 \%$ of the respondents selected the correct option whereas only $08 \%$ of the respondents went for the incorrect option and $04 \%$ of the respondents did not attempt the question. There is no evidence of the selection of any particular distracter. The question may be considered valid and reliable.

The item was selected on the assumption that the analogy is an important part of vocabulary section. The question may be considered valid and reliable.

Q\#11: ODIOUS is the closest in the meaning to?

$100 \%$ of the respondents attempted the question correctly whereas $0.00 \%$ of the respondents chose the wrong option. There is no evidence of the selection of the specific distracter.

The item was selected on the assumption that the knowledge of synonyms is very important in the vocabulary section of any language aptitude test. The question may be considered valid and reliable.

Q\#12: UNDERMINE is the closest in meaning to?

$100 \%$ of the respondents attempted the question correctly whereas $0.00 \%$ of the respondents chose the wrong option. There is no evidence of the selection of the specific distracter. The question may be considered valid and reliable.

The item was selected on the assumption that the knowledge of synonyms is very important in the vocabulary section of any language aptitude test.

Q\#13: TACIT is the closest in meaning to?

$100 \%$ of the respondents attempted the question correctly whereas $0.00 \%$ of the respondents chose the wrong option. There is no evidence of the selection of the specific distracter. The question may be considered valid and reliable.

The item was selected on the assumption that the knowledge of synonyms is very important in the vocabulary section of any language aptitude test.

Q\#14: The opposite of MONOCHROME is?

$68 \%$ of the respondents attempted the question correctly whereas $32 \%$ of the respondents chose the wrong option. There is no evidence of the selection of the specific distracter. The item was selected on the assumption that the knowledge of antonyms is very important in the vocabulary section of any language aptitude test.

Q\#15: The opposite of PERIPHERAL is?

$60 \%$ of the respondents attempted the question correctly whereas $40 \%$ of the respondents chose the wrong option. There is no evidence of the selection of the specific distracter. The question may be considered valid and reliable.

The item was selected on the assumption that the knowledge of antonyms is very important in the vocabulary section of any language aptitude test.

Q\#16: You must buy this before you travel on a train.

$96 \%$ of the respondents attempted the question correctly whereas $04 \%$ of the respondents chose the wrong option. The question may be considered valid and reliable.

The item was selected on the assumption that the contextual based questions provide an ease to solve IQ based items in the vocabulary section.

Q\#17: People carry their clothes in this when they travel.

$92 \%$ of the respondents attempted the question correctly whereas $08 \%$ of the respondents selected the wrong option. The question may be considered valid and reliable.

The item was selected on the assumption that the contextual based questions provide an ease to solve IQ based items in the vocabulary section. 
Q\#18: If you sit next to this, you will see some great views.

$100 \%$ of the respondents attempted the question correctly whereas $0.00 \%$ of the respondents selected the wrong option. The item was selected on the assumption that the contextual based questions provide an ease to solve IQ based items in the vocabulary section.

Q\#19: People wait for their train here.

$100 \%$ of the respondents attempted the question correctly whereas $0.00 \%$ of the respondents selected the wrong option. The question may be considered valid and reliable.

The item was selected on the assumption that the contextual based questions provide an ease to solve IQ based items in the vocabulary section.

Q\#20: There are various stalls to facilitate the train passengers there.

$100 \%$ of the respondents attempted the question correctly whereas $0.00 \%$ of the respondents selected the wrong option. The question may be considered valid and reliable.

The item was selected on the assumption that the contextual based questions provide an ease to solve IQ based items in the vocabulary section.

Hence with the sum of the percentage of the valid items of Section "B" (Vocabulary) is proved valid with $91.63 \%$ of validity with different degrees of individual item's validity in percentage.

\subsection{Section C: (Reading Comprehension)}

Table \# 03 reveals the detailed analysis of the section C (Reading Comprehension). All the five questions were attempted by the respondents. Except the questions \# 23 and 24 all the asked questions proved valid through the SPSS data analysis. Both invalid items proven through SPSS data analysis were neither tricky nor hard. They were asked according to the difficulty level of the students. However, the questions were proved unreliable. The validity of the items would be increased if both of the said items are deleted.

Table \# 03: Detail Analysis of Section C (Reading Comprehension)

\begin{tabular}{|c|c|c|c|c|}
\hline Question \# & Correct Answer (\%) & Wrong Answer (\%) & Un-attempted (\%) & Validity of Question (\%) \\
\hline 21 & 68.00 & 32.00 & 00.00 & 68.00 \\
\hline 22 & 100.0 & 00.00 & 00.00 & 100.0 \\
\hline 23 & 20.00 & 80.00 & 00.00 & 20.00 \\
\hline 24 & 20.00 & 80.00 & 00.00 & 20.00 \\
\hline 25 & 52.00 & 48.00 & 00.00 & 52.00 \\
\hline \multicolumn{4}{|l|}{ Validity as a Whole for Section "C" } \\
\hline
\end{tabular}

\subsubsection{Item Analysis of Section C (Reading comprehension)}

Q\#21: What was the main problem in this story?

$68 \%$ of the respondents attempted the question correctly whereas $32 \%$ of the respondents chose the wrong option. There is no evidence of the selection of the specific distracter. The question may be considered valid and reliable.

The item was selected on the assumption that reading comprehension is a very important part of any language aptitude test.

Q\#22: Why did Chief want to go home?

$100 \%$ of the respondents attempted the question correctly whereas $0.00 \%$ of the respondents chose the wrong option. There is no evidence of the selection of the specific distracter. The question may be considered valid and reliable.

The item was selected on the assumption that reading comprehension is a very important part of any language aptitude test.

Q\#23: Why was the Officer Simpson nervous?

$20 \%$ of the respondents attempted the question correctly whereas $80 \%$ of the respondents chose the wrong option. There is no evidence of the selection of the specific distracter. The question may not be considered valid and reliable.

The item was selected on the assumption that reading comprehension is a very important part of any language 
aptitude test. The item is proved invalid through the SPSS data analysis. The item was not a tough one, but most of the respondents attempted it incorrectly. The reason behind this might be misjudgment due to the haste. The stem and the distracters were very clear otherwise.

Q\#24: Did Chief know what was wrong with Officer Simpson?

$20 \%$ of the respondents attempted the question correctly whereas $80 \%$ of the respondents chose the wrong option. There is no evidence of the selection of the specific distracter. The question may not be considered valid and reliable.

The item was selected on the assumption that reading comprehension is a very important part of any language aptitude test. The item is proved invalid through the SPSS data analysis. The item was not a tough one, but most of the respondents attempted it incorrectly. The reason behind this might be misjudgment due to the haste. The stem and the distracters were very clear otherwise.

Q\#25: "He refused to let that anger show." Which of the following sentence gives closest

sense?

$52 \%$ of the respondents attempted the question correctly whereas $48 \%$ of the respondents chose the wrong option. There is no evidence of the selection of the specific distracter can be seen. The question may or not be considered valid and reliable.

The item was selected on the assumption that reading comprehension is a very important part of any language aptitude test. Hence with the sum of the percentage of the valid items of Section: C (Reading Comprehension) is proved valid with $52.00 \%$ of validity.

\section{Conclusion and Recommendations}

The study was conducted in the department of the English University of Gujrat during Spring- 2012 semester. A question paper was designed to check the aptitude of the intermediate students of population 25 . The reliability and validity of any test need prior examination. The pilot study is considered and recommended by the researchers. Keeping in view the results of the analysis, Section: A (Grammar) was proved valid with $84.33 \%$ of validity. The validity of Section: B (vocabulary) and Section C (reading comprehension) were $91.64 \%$ and 52.00 respectively. As a whole, the validity of all the questions was $75.99 \%$. Thus, the designed aptitude test may be considered reliable. The researchers are of the opinion that in order to plan any aptitude test for best evaluation, pilot studies to check the reliability and validity of the tests are very significant. For the sake of reliable and valid assessment, any institutions must conduct them.

\section{References}

Cameron, William Bruce. (1963). Informal Sociology: A Casual Introduction to Sociological Thinking by www.abebooks.com s

Chalmers, D. (2007). A review of Australian and international quality systems and indicators of learning and teaching. Carrick Institute for Learning and Teaching in Higher Education, 1(2).

Choi, I. C. (2008). The impact of EFL testing on EFL education in Korea. Language Testing, 25(1), 39-62.

Gardner, R. C. (1983). Learning another language: A true social psychological experiment. Journal of language and Social Psychology, 2(2-3-4), 219-239.

Hambleton, R. K., \& Patsula, L. (1999). Increasing the validity of adapted tests: Myths to be avoided and guidelines for improving test adaptation practices. Association of Test Publishers, 1(1), 1-13.

Joe Bower. (2009). For the love of learning. [Online] Available: http://www.youblisher.com/p/7617-For-the-Love-of-Learning/

Joppe, M. (2000). The Research Process. [Online] Available: https://www.uoguelph.ca/hftm/research-process (Feb. 7, 2015).

McClelland, D. C. (1973). Testing for competence rather than for" intelligence.".American psychologist, 28(1), 1. http://dx.doi.org/10.10 $37 / \mathrm{h} 0034092$

Nahid Golafshani (2003). Understanding Reliability and Validity in Qualitative Research. The Qualitative Report, 8(4), 597-606. [Online] Available: http://www.nova.edu/ssss/QR/QR8-4/golafshani.pdf (Feb. 5, 2015).

Trapmann, S., Hell, B., Hirn, J. O. W., \& Schuler, H. (2007). Meta-analysis of the relationship between the Big Five and academic success at university. Zeitschrift für Psychologie/Journal of Psychology, 215(2), 132-151.

Winter, G. (2000). A comparative discussion of the notion of validity in qualitative and quantitative research. The Qualitative Report, 4(3\&4). [Online] Available: http://www.nova.edu/ssss/QR/QR4-3/winter.html. (Feb. 10, 2015). 
Appendix

APTITUDE TEST OF ENGLISH

\section{Total Marks: 25}

Name:

Class:

Roll No:

Maximum Time Allowed: 25 Minutes

Institution:

\section{IMPORTANT NOTE:}

There are three sections of this question paper. All the questions in each section are compulsory. Follow the given instructions carefully. Each correct answer shall carry one mark. Cutting and overwriting shall not be accepted: however, there shall be no negative marking for wrong answer.

\section{SECTION: A (Grammar)}

\section{ENCIRCLE THE CORRECT OPTION:}

1) Did you anywhere last weekend?
a) go
b) going
c) went
d) have gone

2) I work as a teacher and so my wife.
a) do
b) is
c) work
d) does

3) How long married?
a) have you been
b) are you
c) have you
d) been

4) He has not played since he an accident.
a) has
b) had
c) has had
d) had had

5) He is good Mathematics.
a) in
b) at
c) for
d) of

6) I_ a book now-a-days.
a) was writing
b) am writing
c) have written
d) will write

7) I have not seen him a long time.
a) since
b) to
c) from
d) for

8) If she works hard, she the test.
a) passes
b) pass
c) will pass
d) will have pass

9) Zafer in the factory for ten years.
a) worked
b) has been working
c) have been working
d) is working 


\section{SECTION: B (Vocabulary)}

\section{ENCIRCLE THE CORRECT OPTION:}

10) Cow: Calf:
a) Hen: Egg
b) Horse: Mare
c) Ram: Ewe
d) Goat: Kid

11) ODIOUS is the closest in the meaning to?
a) Hateful
b) Blunt
c) Neutral
d) Faithful

12) UNDERMINE is the closest in meaning to?
a) Impose
b) Apprehend
c) Glorify
d) Weaken

13) TACIT is the closest in meaning to?
a) Ostensible
b) Garrulous
c) Peaceful
d) Unspoken

14) The opposite of MONOCHROME is?
a) Variegated
b) Multidimensional
c) Complex
d) Bicameral

15) The opposite of PERIPHERAL is?
a) Central
b) Spherical
c) Exterior
d) Radial

FILL THE FOLLOWING BLANKS WITH APPROPRIATE WORDS BY USING THE GIVEN FIRST ALPHABET OF EACH EXPECTED WORD.

16) You must buy this before you travel on a train

$\mathrm{T}$

(Expected word is of 06 letters)

17) People carry their clothes in this when they travel.

B

(Expected word is of 03 letters)

18) If you sit next to this, you will see some great views.

W

(Expected word is of 06 letters)

19) People wait for their train here.

W

(Expected word is of 11 letters)

20) There are various stalls to facilitate the train passengers there.

PLAT FORM

(Expected word is of 08 letters) 


\section{SECTION: C (READING COMPREHENSION)}

\section{READ THE FOLLOWING PASSAGE CAREFULLY AND ENCIRCLE THE CLOSEST GIVEN ANSWER FOR EACH QUESTION BELOW:}

Frank Wilcox has been Chief of police in a Lansett county for 25 years. He had just turned 30 when he took the job. He has seen murders, robberies and cats stuck in trees. He has found missing children. Today would be like no other. It is 11:00 at night. Chief Wilcox was putting together his things. He was tired. He wanted to go home. "Chief Wilcox," an officer shouted while walking quickly into his office. It was Officer Simpson. He looked nervous. He looked like he would like to be anywhere else but there. "What is it, Simpson?" asked the Chief. "Holman's Grocery is just held up at gun point," Simpson said. His voice was shaky. He coughed to clear his throat. "Is anyone hurt?" asks Chief. Lansett is a very small county. The Chief knew just about everyone who lived there. If anyone was hurt, there was a good chance he knew who was it? May be that's why Officer Simpson looked nervous. "No one is hurt "Simpson replied". "But we caught the suspect." "Ah, well, Simpson. You guys could take care of that. I' was--," Chief Wilcox stopped in mid-sentence. He understood what was wrong. From behind Officer Simpson, the Chief saw his youngest daughter, Devon. She was in handcuffs. Chief Wilcox got a lump in his throat. He sat in his chair, stunned. "How could it be?" he thought. "Devon, would you please tell me what is going on?" the Chief demanded. Devon did not look at him. The Chief could feel anger growing inside of him. He refused to let that anger show. "Take her back for questioning" the Chief said to Officer Simpson in a calm voice. "Devon, whatever you did, speak the truth," the Chief said. "I'm your dad. I love you. We will figure this out."

21) What was the main problem in this story?
a) Devon won't look at her dad.
b) Officer Simpson was nervous.
c) The Chief's daughter was caught of theft.
d) The Chief wanted to go home.

22) Why did Chief want to go home?
a) He was hungry.
b) He was tired.
c) He wanted to see Devon
d) He was worried about his family.

23) Why is Officer Simpson nervous?

a) He is scared of Chief Wilcox.

b) He has just been held up at gun point.

c) He has just arrested Chief's daughter.

d) He has just found an important piece of evidence in a new case.

24) Did Chief know what was wrong with Officer Simpson?
a) Yes
b) No
c) Might be
d) a \& $c$

25) "He refused to let that anger show." Which of the following sentence gives closet sense?
a) He is forced to let that anger show.
b) He is about to let that anger show.
c) He wants to let that anger show.
d) He disguised his anger.

(Nice Attempt, Good Luck) 